\title{
BECCS in South Korea - An Analysis of Negative Emissions Potential for Bioenergy as a Mitigation Tool
}

\author{
Florian Kraxner ${ }^{1, *}$, Kentaro Aoki ${ }^{1}$, Sylvain Leduc ${ }^{1}$, Georg Kindermann ${ }^{1}$, Jue Yang ${ }^{2}$, \\ Yoshiki Yamagata $^{2}$, Kwang Il Tak ${ }^{3}$, Michael Obersteiner ${ }^{1}$ \\ ${ }^{1}$ Forestry Program, International Institute for Applied Systems Analysis (IIASA), Laxenburg, Austria \\ ${ }^{2}$ Center for Global Environmental Research (CGER), National Institute for Environmental Studies (NIES), \\ Tsukuba, Japan \\ ${ }^{3}$ Forestry Department, Kookmin University, Seoul, Republic of Korea \\ * Corresponding author. Tel: +43 2236807 233, Fax: +43 2236807 299, E-mail: kraxner@iiasa.ac.at
}

\begin{abstract}
The objective of this study is to analyze the in-situ BECCS capacity for green field bioenergy plants in South Korea. A technical assessment is used to support a policy discussion on the suitability of this mitigation tool. We first examined the technical potential of bioenergy production from domestic forest biomass. For this exercise, in a first step, the biophysical Global Forestry Model G4M was applied in order to estimate the biomass availability. In a second step, the biomass results from the forestry model were used as input data for an engineering model (BeWhere) for optimized scaling and locating of coupled heat and power plants (CHP). The obtained geographically explicit locations and capacities for forest-based bioenergy plants were then overlaid with a geological suitability map for carbon storage. From this, a theoretical potential for in-situ BECCS was derived. Results indicated that, given the abundant forest cover in South Korea, there is a substantial potential for bioenergy production which could contribute to substituting emissions from fossil fuels and to meeting the targets of the country's commitments under any climate change mitigation agreement. However, there seems to be only limited potential for direct in-situ carbon storage in South Korea.
\end{abstract}

Keywords: BECCS, Bioenergy, Carbon Capture and Storage, Biomass modeling, Energy policy

\section{Introduction}

An active debate in the scientific community is revolving around the possibility of using bioenergy in combination with carbon capture and storage (BECCS), which could remove $\mathrm{CO}_{2}$ from the atmosphere in order to contribute substantially to achieving low levels of concentration. In the Fourth Assessment Report of the Intergovernmental Panel on Climate Change (IPCC), BECCS is considered "a potential rapid-response prevention strategy for abrupt climate change" and is consequently considered as one of the options to comply with the targets agreed in the Kyoto Protocol [1]. During the last decade it was demonstrated by e.g. [2-4] that terrestrial ecosystems when combined with the use of biomass energy can offer a permanent carbon sink by capturing carbon from biomass conversion facilities and permanently storing carbon in geological formations. However, compared to CCS (Carbon Capture and Storage) combined with conventional fossil fuel systems, very little information can be found in scientific literature so far for both the technical and potential application of BECCS. Moreover, apart from engineering papers presented at e.g. special BECCS conferences such as [5] on Europe, there is - according to our knowledge - to date no literature available that features geographic explicit BECCS applications, especially not for non-European countries.

Although the land base of Korea is small, as much as $64 \%$ of the country is forested. Due to a highly efficient and rapid national reforestation program in the 1970s, a majority of the forests in Korea has now reached age classes of 30 and 40 years, which require intensive care in terms of thinning and pruning. By-products from these silvicultural activities can generate a significant amount of raw material to produce e.g. wood pellets and wood chips. Korea 
appears further to be an interesting study area for bioenergy, since the country's forestry regained importance both from an ecological as well as from an economical point of view only recently. While trying to build up a bioenergy sector for both energy security and contributing to reduce $\mathrm{CO}_{2}$ emissions in order to comply with climate change mitigations efforts, sustainable forest management is seen as a key for mobilizing forest biomass for energetic use or direct carbon sequestration. Consequently, ambitious policies and plans for bioenergy production were introduced by the country's government (e.g. "Low Carbon Green Growth" initiative by the National Energy Plan [6]). However, the lack of forestry infrastructure such as adequate forest roads - for important management activities like harvesting or replanting - causes still too high costs for biomass and related energy production [e.g. 7]. Moreover, this alternative energy sector is facing strong competition from e.g. lower cost fossil and nuclear energy sectors. Hence, being able to better quantify the sustainable bioenergy potential in these countries by identifying economically and biophysically optimized locations for new bioenergy plants and adding value to this information by selecting those locations with promising in-situ combination with CCS technology, policy makers in Korea would be able to develop and support improved and better targeted policies in the area of energy, climate and environment while being supportive to various co-benefits such as rural development, (re-) activation of sustainable forest management etc. The aim of the technical part of our manuscript was threefold. First, to help identifying - in a geographically explicit manner - the available biomass from forest for bioenergy production under sustainable management conditions in South Korea; second, to indicate the optimal size and location of green-field forest biomass-based bioenergy CHP (Coupled Heat and Power technology) plants; and third, to identify the amount and capacity of in-situ BECCS units in South Korea.

\section{Method}

There are various systems for CCS, such as underground geological storage, ocean storage, mineral carbonation, or industrial use. In this study, we considered the CCS System (with post combustion capture technology) for the underground geological storage into a certain geological formation in the on-shore earth's subsurface. Additionally, we were especially aiming at direct "in-situ" storage. The storage happens in direct vicinity to the combustion units (CHP plants) in order to minimize transport costs and complications. Further we assumed that the total amount of $\mathrm{CO}_{2}$ - emissions generated at a BECCS unit will be captured and stored in-situ. A technical assessment was used to support a policy discussion on the suitability of this mitigation tool. We first examined the technical potential of bioenergy production from domestic forest biomass. For this exercise, in a first step, the biophysical global forestry model G4M [8] was applied in order to estimate the biomass availability. In a second step, the biomass results from the forestry model were used as input data for the engineering model BeWhere [9] for optimized scaling and locating of CHP plants. The obtained geographically explicit locations and capacities for forest-based bioenergy plants were consequently overlaid with a geological suitability map for carbon storage. From this, a theoretical potential for "in-situ” BECCS was derived.

\subsection{The Global Forest Model (G4M)}

The Global Forest Model (G4M) from IIASA was used to calculate the growing stock and the sustainable biomass extraction rate. G4M, as described by [8], has been developed in order to predict wood increment and stocking biomass in forests. As input parameter it uses yield power which is achieved through the net primary productivity (NPP) for a specific region. This NPP can be supplied by existing NPP-maps [e.g. 10] or - for higher accuracy estimated with the help of driver information of soil, temperature and precipitation. The 
model can be used like common yield tables to estimate the increment for a specific rotation time. It can further be used to estimate the increment- related optimal rotation time and to provide information on how much biomass can be harvested under a certain rotation time and how much biomass is stocking in the forest. G4M also supplies information on the harvesting losses like needles, leaves and branches which typically remain in the forests under sustainable management. Further, other economic parameters such as harvesting costs depending on tree size and slope - can be calculated.

\subsection{The BeWhere Model}

The BeWhere Model - a spatially explicit optimization model, depicting the supply chain of bioenergy industries - was used for the in-situ BECCS assessment [9]. The model, developed at IIASA, considers industries competing for wood resources. On the supply side, forest wood harvests, sawmill co-products (SCP) and wood imports serve as biomass resources for possible new bioenergy plants. Wood demand of pulp-and-paper mills, of existing bioenergy plants and of private households is considered on the demand side The model assumes that the existing wood demand has to be fulfilled, allowing new plants to be built only if there is enough surplus of wood available. The model is spatially explicit and the transportation of wood from biomass supply to demand spots is considered either by truck, train or boat. The model selects optimal locations of green-field bioenergy plants by minimizing the costs of biomass supply, biomass transport and energy distribution. Full costs and emissions at the optimal locations were calculated such that we were able to indicate the BECCS potential for the country under investigation. Spatial distribution of forestry yields was estimated and provided by the G4M, as well as the harvesting costs (as a function of tree size depending on site quality and rotation time) and the slope steepness were provided by the same model.

\section{Results}

There were 3 complementary main sets of results derived from this study and indicated at country level: 1) the sustainably available biomass potential for harvest together with the national heat demand as a main prerequisite for the installation of green-field CHP plants; 2) the geological suitability for CS (Carbon Storage); and 3) the identified locations for BECCS units together with their individual bioenergy production capacity as well as their carbon capture and storage capacity. All presented geographically explicit data sets were compiled at a 0.25 -deg (degree grid cell) resolution $(25 \times 25 \mathrm{~km})$. We used a conversion factor of 0.5 to estimate dry matter biomass (ton dry matter, tdm) from stem volume irrespective to the tree species. The defined forest harvesting scenarios were based on the amount of extracted biomass, while the baseline for harvesting was considered under a sustainable forest management regime, assuming that the average annual harvesting rate is substantially lower than the annual allowable cut. We further assumed that only stem biomass was extracted from the forest stands and that $100 \%$ of the extracted biomass was used for energy production. Following conversion factor for the national currency was applied for economic calculations of harvesting, transport and energy (heat) costs: 1 Korean Won $=0.000908987$ USD (2008).

\subsection{Biomass availability and energy demand}

For our analysis, we assigned a managed forest area of 4,852,330 ha (about $78 \%$ of total South Korean forest area) for biomass extraction dedicated to energy production. This forest area was modeled as an aggregated forest cover map based on GLC 2000 [11], the Relative Human Influence concept for each terrestrial biome [12], a classification of pristine and nonpristine forest [13] and protected area [14]. We excluded the forest area where the Relative Human Influence was less than $50 \%$ and where protected areas designated by IUCN 
Categories I - VI were located. For the geographical distribution of the actual growing stock we calculated 555,363,300 $\mathrm{m}^{3}$ (protected area excluded), which was achieved with the help of the global biomass map [15] which was harmonized with FAO statistics of 2005 [13], while the official national statistics of South Korea reported a total growing stock of 506,376,806 m3 for 2005 [16]. Derived from Korean forest statistics in 2008, we limited the biomass extracted annually for energy production to $0.36 \%$ of the total growing stock (sustainable forest management criteria), amounting 999,653 tdm/year (on average $1.62 \mathrm{tdm} /$ ha-year) - see Fig. 1 for the spatial distribution. Further information for our economic optimization process with respect to costs (wood chip and stumpage price, harvesting and extraction costs) were derived from various Korean resources and adapted to local slope conditions for harvesting operations with different technologies.

In South Korea, the total heat energy consumption was 625,915 GJ/year in 2008 [6]. As input for the energy demand calculations, we geographically weighted the heat demand with the population for 2005 at 0.25 degree resolution and assumed that the average heat demand per person was $0.0127 \mathrm{GJ} /$ person (Fig. 1). The average energy prices for Korea in 2008 were adapted from the national statistics.

The demand-supply optimization routines of the BeWhere model also consider transportation costs (truck, train, ship - derived from [17]), as well as the existing road and railway networks for South Korea which were taken from vmap0 [18], also considering different travel speeds.

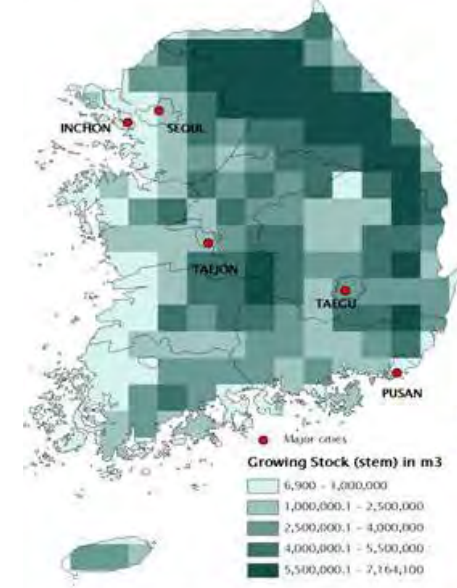

Modeled Growing Stock

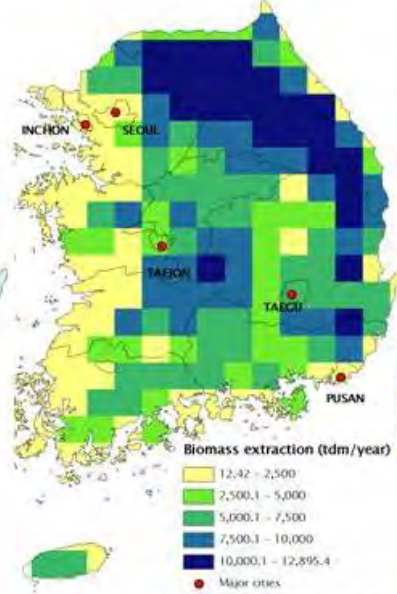

Potential Biomass Extraction

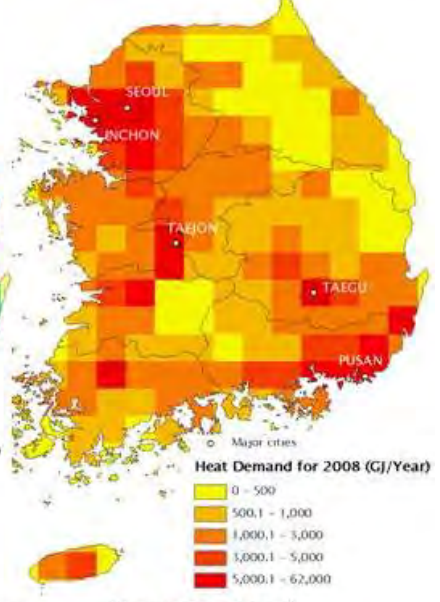

Heat Demand

Fig. 1. Geographically explicit supply - demand situation for Korea. The map on the left hand side indicates the modeled spatial distribution of the growing Stock $\left(\mathrm{m}^{3}\right)$ in Korean forests (biomass supply). The highest growing stock could be identified in the north-east and the center of Korea (dark pixels). The map in the center indicates the modeled potential biomass extraction rate (tdm/year) - under sustainable conditions - from Korean forests (biomass supply). Highest biomass extraction rates could be achieved also in the north-east and center of the country. The map on the right hand side indicates the modeled spatial distribution of the heat demand (GJ/year). Highest demand was identified around the large urbanized areas (e.g. Seoul) in the western and south-eastern part of the country.

\subsection{Identification of geological suitability for $C$ - storage}

The geological CS facility can be installed only under specific conditions such as geological characteristics (e.g. tectonic activity, sediment type, geothermal and hydrodynamic regimes) and maturity of infrastructure to build CCS units. In general, sedimentary basins are the sites with the highest potential for geological CS. Suitable sites for geological $\mathrm{CO}_{2}$ storage can be found on: 1) basins formed in mid-continent locations, 2) basins formed near the edge of stable continental plates, 3) basins behind mountains formed by plate collision such as European 
basins immediately north of the Alps and Carpathians, 4) fold belts, and 5) some of the highs [e.g. 1]. Other geological formations such as shield areas (e.g. Scandinavia) or tectonically active areas (e.g. Japan) are less suitable for geological $\mathrm{CO}_{2}$ storage. However, the suitability for geological CS depends to a great extent on their local conditions. We identified mostly basins as potentially suitable locations for geological in-situ CS in South Korea. The geological map shown in Fig. 2 was mainly based on the studies by [19] and [20]. The location for $\mathrm{CO}_{2}$ injection can be different from the site of the bioenergy plants where $\mathrm{CO}_{2}$ emissions occur. In the case of South Korea mainly the geological Gyeongsang Basin located in the south-east of the country could be identified to be potentially suitable for in-situ CS.

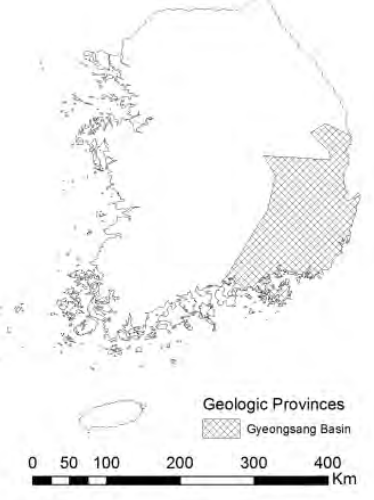

Fig. 2 Potential locations (Geologic Province) suitable for geological CO2 storage in South Korea (on-shore only). Source: modified after [19] and [20].

\subsection{Potential in-situ BECCS units identified for South Korea}

To identify the optimal locations for green-field bioenergy plants, three different sizes of CHP plants are considered $(5,20$, and $70 \mathrm{MW})$. We assumed that diversification with respect to plant size would on the one hand result in a better distribution of plants within the country, which increases usually also the co-benefits of bioenergy plants. On the other hand we expected to identify more bioenergy plants suitable for in-situ CS. Within each scenario (plant capacity) the aim was to meet the target for the maximum sustainable biomass extraction (about $1 \mathrm{M}$ tdm/year).
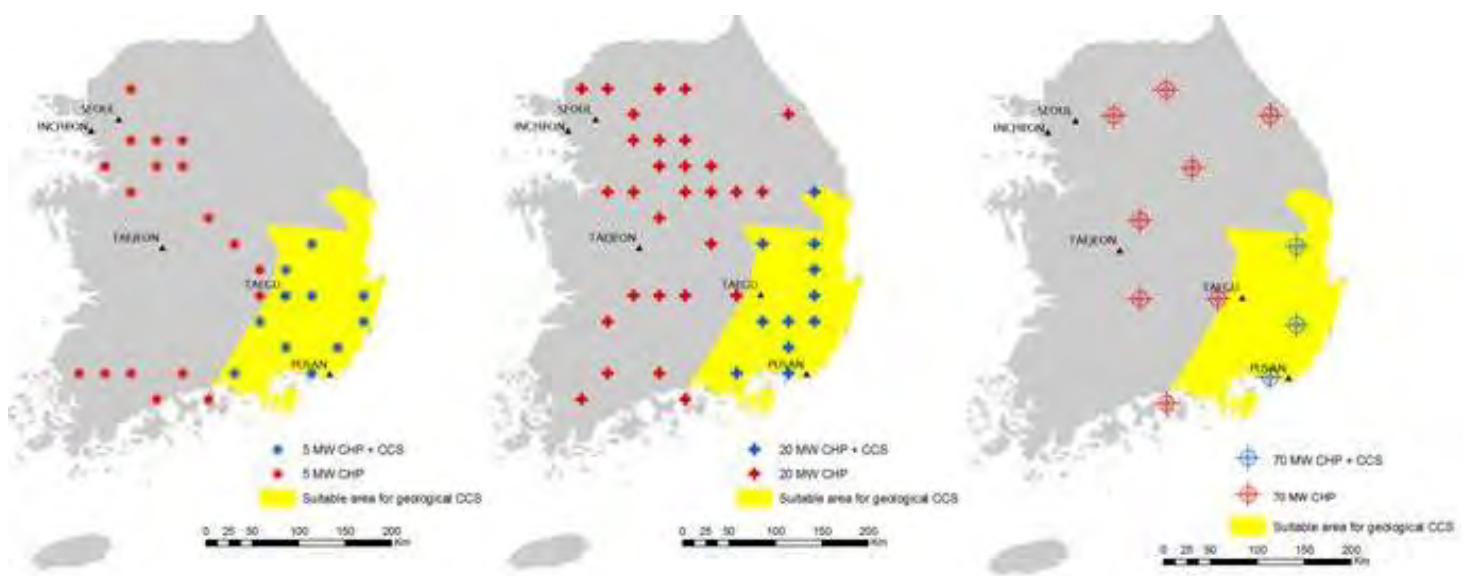

Fig. 3. Three different scenarios (from left to right 5; 20; $70 \mathrm{MW}$ ) for optimized green-field biomass plant locations in South Korea. The geographic explicit location of bioenergy plants without CCS is indicated in red color and the BECCS unit locations are indicated in blue color on light yellow background (geologically suitable formation for CS).

For this study we defined in-situ CS suitability such that the bioenergy plant needs to be located within a 0.5 degree grid cell (about 55 x $55 \mathrm{~km}$ ) of the suitable geologic province in 
order to directly inject CO2 underneath a plant or at any place up to a maximum of $25 \mathrm{~km}$ radius distance (e.g. with the help of a short pipeline).

Based on these assumptions, Fig. 3 shows the optimized location in a geographically explicit manner by plant size. Table 1 indicates the optimized amount of green field bioenergy plants for Korea, listed by plants with and without in-situ CS suitability, divided into the different plant capacity categories.

Table 1. Energy produced, emissions substituted and CCS Capacity by forest biomass CHP plants with/without BECCS system under a sustainable forest biomass production regime.

\begin{tabular}{|c|c|c|c|c|c|c|}
\hline Plant size Technology & $\begin{array}{c}5 \mathrm{MW} \\
\text { NO CCS }\end{array}$ & $\begin{array}{c}\text { 20 MW } \\
\text { NO CCS }\end{array}$ & $\begin{array}{c}70 \mathrm{MW} \\
\text { NO CCS }\end{array}$ & $\begin{array}{c}5 \mathrm{MW} \\
\text { CCS }\end{array}$ & $\begin{array}{c}20 \mathrm{MW} \\
\text { CCS }\end{array}$ & $\begin{array}{c}70 \mathrm{MW} \\
\text { CCS }\end{array}$ \\
\hline Plant \# & 18 & 29 & 8 & 11 & 11 & 3 \\
\hline Biomass used (tdm/year) & 117,000 & 716,300 & 712,400 & 71,500 & 271,700 & 267,150 \\
\hline Heat produced (GJ/year) & $1,190,475$ & $7,288,353$ & $7,248,670$ & 727,513 & $2,764,548$ & $2,718,251$ \\
\hline El. produced (GJ/year) & 757,575 & $4,638,043$ & $4,612,790$ & 462,963 & $1,759,258$ & $1,729,796$ \\
\hline Subst. emissions (tCO $/$ year) & 215,516 & 627,050 & 625,036 & 131,704 & 237,847 & 234,389 \\
\hline CCS Capacity (tCO2/year) & $\mathbf{0}$ & $\mathbf{0}$ & $\mathbf{0}$ & $\mathbf{1 3 1 , 7 0 4}$ & $\mathbf{2 3 7 , 8 4 7}$ & $\mathbf{2 3 4 , 3 8 9}$ \\
\hline
\end{tabular}

We could identify a maximum of 40 green-field bioenergy plants under the $20 \mathrm{MW}$-scenario of which 11 plants were located on geologically suitable ground in order to meet the criteria for BECCS units. Under the $5 \mathrm{MW}$ scenario, 29 bioenergy plants were optimally distributed over the country, among which also 11 plants qualified as BECCS plants. Under the $70 \mathrm{MW}$ scenario a total of 11 bioenergy plants were computed of which 3 met the criteria for BECCS units. In the best case (20 MW scenario), the "BECCS-effect" (emissions accounted as negative) could reach a potential capacity of some 238,000 tons of $\mathrm{CO}_{2}$ to be directly stored permanently belowground per year and to be accounted as negative emissions.

\section{Discussion and Conclusions}

Our BECCS exercise offers several new insights to the bioenergy sector in South Korea and provides crucial information for policy support and design. First of all, it is important to note that even under our rather conservative assumptions - especially with respect to sustainable biomass extraction - we still could theoretically produce some $10 \%$ of the present heat demand (being equivalent to a 20 times increment of the present bioenergy share for heat production in Korea [21]), and 1.3\% of the total electricity produced in South Korea (15 times the present bioenergy share for electricity production [21]). These results indicate a substantial potential of bioenergy growth in South Korea - especially given the present policies and targets of the National Energy Plan to e.g. increase the bioenergy share in total energy production from $0.2 \%$ (2007) to $3.4 \%$ by 2030 [6].

Among the 3 different scenarios (plant capacities), the $20 \mathrm{MW}$ scenario turned out to offer the best country-wide coverage with its 40 green-field bioenergy facilities, which consequently could provide direct and indirect co-benefits such as driving the green economy, i.e. providing job opportunities both at the facility and in the biomass production. Another major benefit of growth in the bioenergy sector would be the resulting investments in forest and forest management primarily by small-scale forest owners, e.g. in forest infrastructure. These benefits are based on the assumption that forest biomass would see a price increase, which justifies investments into forest infrastructure (to harvest the biomass more easily) which lowers harvesting costs and increases competitiveness. 
Although the suitable geological formations for in-situ CS in South Korea are limited to about $1 / 5$ of the country area (the Gyeongsang Basin), with the help of this study we could show that there is a theoretical potential for 3 (70 MW plants) to 11 (5 / $20 \mathrm{MW}$ plants) green-field BECCS plants with in-situ CS. Based on our assumptions, the BECCS-effect might amount to $130,000-240,000$ tons $\mathrm{CO}_{2}$ per year in addition to a similar amount of substituted fossil fuel emissions. This means that about $3-4 \%$ of the total demand for heat energy in South Korea could be produced in BECCS plants with in-situ CS. As a consequence, 3-4\% of the fossil fuel emissions could be substituted and additionally accounted as negative because they would be actively removed from the atmosphere by BECCS plants. This BECCS effect comes additionally to the biomass co-benefits discussed earlier and could be used as a key issue for future policy design and decision makers.

However, the BECCS effect - and with it a crucial lever for climate, environment and rural development policies - could certainly be substantially increased and strengthened. An important caveat to bear in mind is that with our study we only could point out the theoretical potential without considering the costs of the actual CCS process. If bioenergy plants with higher capacities would be applied, costs could be substantially decreased (scale effect or poly-production). Further, although the suitable geological formations for geological CCS appearing in South Korea are limited (e.g. earthquake and volcanic activity), there are wide off-shore prospective areas in this region (e.g. East Sea). Using further capacity for CS (non in-situ), basically all substituted emission from bioenergy production could additionally be stored and accounted as negative. The use of a (trans-national) $\mathrm{CO}_{2}$-pipeline could actually boost the BECCS effect and lower the costs, but further research needs to be done in this field. Also the joint use of off-shore CS together with e.g. Japan would substantially increase BECCS capacity, which requires similar research to be extended to South East Asia, potentially using a higher data resolution than 0.25 -deg.

We conclude that policy targeted bioenergy-based re-activation of forest management in South Korea would evoke a real win-win-situation. First, bioenergy production and BECCS would directly contribute to meet ambitious climate change mitigation targets. Second, the forest ecosystem would benefit from sustainable management (including thinning etc.) e.g. in terms of improved forest health, stand stability and lower exposure to threatening hazards like wind throw or pests. Third, the forest owners - and with them the forest sector industry would benefit from an increased value of the forest property, from better prized forest products, as well as from a higher quality of the grown timber and competitive harvesting conditions as a consequence of investment into forest infrastructure. And last not least, society would benefit through e.g. an improved protective function (from e.g. flooding, landslides, avalanches etc.) and an increased recreational value of the forest.

\section{References}

[1] IPCC, Special Report on Carbon Dioxide Capture and Storage. ISBN-13 978-0-52186643-9. Cambridge University Press, 2005.

[2] M. Obersteiner, C. Azar, P. Kauppi, K. Möllersten, J. Moreira, S. Nilsson, P. Read, K. Riahi, B. Schlamadinger, Y. Yamagata, J. Yan, J-P. van Ypersele, Managing climate risk, Science 294(5543), 2001, pp. 786-787.

[3] F. Kraxner, S. Nilsson, M. Obersteiner, Negative emissions from BioEnergy use, carbon capture and sequestration (BECS) - the case of biomass production by sustainable forest management from semi-natural temperate forests, Biomass and Bioenergy 24, 2003, pp. 285-296. 
[4] C. Azar, K. Lindgren, M. Obersteiner, K. Riahi, D.P. van Vuuren, K.M.G.J. den Elzen, K. Möllersten, E.D. Larson, The feasibility of low $\mathrm{CO}_{2}$ concentration targets and the role of bioenergy with carbon capture and storage (BECCS). Climatic Change 100, 2010, pp. 195-202.

[5] F. Kraxner, G. Kindermann, S. Leduc, K. Aoki, M. Obersteiner, Bioenergy Use for Negative Emissions - Potentials for Carbon Capture and Storage (BECCS) from a Global Forest Model Combined with Optimized Siting and Scaling of Bioenergy Plants in Europe. Paper presented at the First International Workshop on Biomass \& Carbon Capture and Storage October 2010, University of Orléans, France, 2010.

[6] Korea Energy Management Corporation, 2010, available at: http://www.kemco.or.kr/new_eng/main/main.asp

[7] F. Kraxner, J. Yang, Y. Yamagata, Attitudes towards forest, biomass and certification A case study approach to integrate public opinion in Japan. Bioresource Technology, 100(17), 2009, pp. 4058-4061.

[8] G. Kindermann, M. Obersteiner, B. Sohngen, J. Sathaye, K. Andrasko, E. Rametsteiner, B. Schlamadinger, S. Wunder, R. Beach, Global cost estimates of reducing carbon emissions through avoided deforestation, PNAS 105(30), 2008, pp. 10302-10307.

[9] S. Leduc, E. Schmid, M. Obersteiner, K. Riahi, Methanol production by gasification using a geographically explicit model. Biomass and Bioenergy, 33(5), 2009, pp. 745-751.

[10]S.W. Running, Terrestrial remote sensing science and algorithms planned for EOS/MODIS. International Journal of Remote Sensing 15, 1994, pp. 3587-3620.

[11]JRC Global Land Cover 2000 version 1. Database. Joint Research Centre, European Commission, 2000, http://bioval.jrc.ec.europa.eu/products/glc2000/products.php

[12]WCS-CIESIN, Last of the Wild Data Version 2, 2005 (LWP-2): Global Human Footprint data set (HF), 2005, http://sedac.ciesin.columbia.edu/wildareas/downloads.jsp\#infl

[13]FAO Global Forest Resources Assessment 2005. FAO Forestry Paper 147. Food and Agriculture Organization of the United Nations, Rome, 2005.

[14]UNEP-WCMC, World Database on Protected Areas (WDPA), United Nations Environment Programme World Conservation Monitoring Centre, 2009.

[15] G. Kindermann, I. McCallum, S. Fritz, M. Obersteiner, A global forest growing stock, biomass and carbon map based on FAO statistics. Silva Fennica 42(3), 2008, pp. 387-396.

[16]Korea Forest Service, Statistical Yearbook of Forestry 2009. Korea Forest Service, Daejeon, 2009.

[17]P. Börjesson, L. Gustavsson, Regional Production and Utilization of Biomass in Sweden. Energy 21, 1996, pp. 747-764.

[18] National Imagery and Mapping Agency, World roads (VMAP0) Fairfax, VA: National Imagery and Mapping Agency, 1997

[19] J.B. Bradshaw, T. Dance, Mapping geological storage prospectivity of $\mathrm{CO}_{2}$ for the world sedimentary basins and regional source to sink matching, GHGT-7, September 5-9, 2004, Vancouver, Canada, v.I, pp. 583-592.

[20]USGS, U.S. Geological Survey World Petroleum Assessment 2000 - Description and Results, DDS-60. United States Geological Survey, 2001.

[21]IEA, International Energy Agency, Country Statistics, 2008, available at: http://www.iea.org 